\title{
Analysis of Covid-19 Complications in Diabetic Patients
}

\author{
Kaushiki Dubey ${ }^{1}$, Komal Meshram² and Dhruba Hari Chandi ${ }^{3}$ \\ ${ }^{1}$ Student Datta Meghe Medical College, Datta Meghe Institute of Medical Sciences, Nagpur, India \\ ${ }^{2}$ Dept. of Physiology Datta Meghe Medical College, Datta Meghe Institute of Medical Sciences, Nagpur \\ ${ }^{3}$ Dept. of Microbiology Jawaharlal Nehru Medical College, Datta Meghe Institute of Medical \\ Sciences Sawangi (Meghe), Wardha \\ Corresponding author email: kaushikidubey01@gmail.com
}

\section{ABSTRACT}

Currently, the whole world is facing the pandemic which is caused by covid-19 or SARS-CoV-2. The corona virus infection with its mutant strains is causing massive, rapid transmission globally. Its most common symptoms are fever, dry cough, headache, running nose, body ache and sometimes diarrhoea too. The underlying medical problems like diabetes mellitus and old age are some factors which may contribute to the severity of the disease. Since, the diabetic patients are immunocompromised; they must take proper care necessary precautions against the covid-19 infection. If there is infection in diabetic patients, then frequent monitoring of blood sugar level is required. The patients with uncontrolled diabetes are at higher risk of hospitalization and mortality. Thus, covid-19 results in worsening of the diabetic conditions. But, the reason behind this is still not clear, as the evidences available are limited.

KEY WORDS: COVID-19, SARS-COV-2, DIABETES MELLITUS, COMPLICATIONS AND MORTALITY.

\section{INTRODUCTION}

COVID-19 is an infectious disease caused by a newly discovered novel corona virus or severe acute respiratory syndrome corona virus 2 (SARS-CoV-2) (Roncon et al. 2020; Tadic et al., 2020; Huang et al., 2020). It was first observed in the Wuhan district of China, on December 31st, 2019 (Abdi et al., 2020). Starting then, it has been rapidly spreading all over the world. Most of the covid19 patients experiences mild to moderate respiratory symptoms such as fever, dry cough and headache. Those people who have underlying medical problems like diabetes mellitus, hypertension may suffer from severe complications, if infected with covid-19 (Parveen et al.,

Biosc Biotech Res Comm P-ISSN: 0974-6455 E-ISSN: 2321-4007

\section{crossef}

Identifiers and Pagination

Year: 2021 Vol: 14 No (6) Special Issue

Pages: 49-51

This is an open access article under Creative

Commons License Attribn 4.0 Intl (CC-BY).

DOI: $h t t p: / / d x . d o i . o r g / 10.21786 / b b r c / 14.6 .11$
2020; Anuja et al., 2020; Hussain et al., 2020; Pugliese et al., 2020).

Diabetes mellitus is a chronic metabolic disease characterized by elevated blood sugar levels (Pugliese et al., 2020). The most common type is type 2 diabetes or insulin- independent diabetes, which usually occurs in adults (Baidya et al., 2020; Vaibhav et al., 2020). It is seen that the diabetic patients are more prone to covid-19 infection (Muniyappa and Gubbi, 2020; AbuFarha et al., 2020). Also, they are at higher risk of having complications, which may ultimately lead to higher mortality rate (Pal et al., 2020). However, some studies show that there is not enough evidence to elaborate the effect of corona virus in diabetes.

Effects of covid-19 on diabetic patients: Several researchers and a number of studies have analyzed the co-relation between diabetes and covid-19 severity. It is seen that corona virus has a bad effect of diabetic patients (Rajpal et al., 2020; Kaple et al., 2020; Zhou and Tan, 2020; Kumar et al., 2020; Zhang et al., 2020). It is also observed that the maximum percentage of the hospitalized corona patients are diabetic. A few studies 
proposed that, the patients with diabetes and covid-19 are likely to have higher chances of ICU (Intensive Care Unit) admission (Jayshri Sadashiv et al., 2020; Priyal et al., 2020; Yaribeygi et al., 2020., Kosinski et al., 2020). Therefore, in these type of patients there is high risk of severity and mortality.

The factors contributing to the complications in the patients with diabetes and covid-19 are still not clear because the current evidences are limited. Since,the innate immunity in the diabetic patients is low; they are more prone to complications (Villabona, 2020). It is also observed that not all diabetic patients may suffer from co morbidities. Also, it is found that the occurrence of severe complications is more in those individuals with uncontrolled diabetes as compared to the controlled ones (Nida Taher et al., 2020; Poonam et al., 2020; Stehouwer et al., 2021).Apart from the poorly controlled diabetes other factors like old age, high cholesterol levels also contribute to the severity of the disease.

According to a statement released by the International Diabetes Federation (IDF), diabetes patients' symptoms are similar to those of other COVID-19 patients (Ashfaque et al., 2020).Diabetic patients, on the other hand, are thought to have more evolved symptoms.In diabetic patients with COVID-19 infection, glycemic variability is a prognostic factor. The cytokine storm, endothelial dysfunction, and multiple organ injuries that hyperglycemia causes worsen the outcome (Kaple et al., 2020). COVID-19 infection exacerbates diabetes mellitus stress by releasing glucocorticoids and catecholamines into the bloodstream. These wreak havoc on glycemic regulation and increase the formation of glycation end products in a variety of organs, both of which worsen prognosis.

\section{CONCLUSION}

Therefore, it is observed that the covid-19 has an adverse effect on the diabetic patients, especially in the uncontrolled ones. This may ultimately lead to higher mortality rate. No definite statement can be made regarding the effects of covid-19 in diabetes. Due to the limited resources, a detailed analysis between covid-19 and diabetes is yet to be concluded by the researchers.

\section{REFERENCES}

Abdi, A., Jalilian, M., Sarbarzeh, P.A. and Vlaisavljevic, Z., 2020. Diabetes and COVID-19: A systematic review on the current evidences. Diabetes research and clinical practice, 166, p.108347.

Abu-Farha, M., Al-Mulla, F., Thanaraj, T.A., Kavalakatt, S., Ali, H., Abdul Ghani, M. and Abubaker, J., 2020. Impact of Diabetes in Patients Diagnosed With COVID19. Frontiers in immunology, 11, p.3112.

Ashfaque, A.R.M., Khanam, N., Khan, F., Waghmare, R.N. and Joshi, S.K., 2020. Assessment of Self-Care Practices among Type 2 Diabetes Patients at a Tertiary Care Hospital--A Cross-Sectional Study. Journal of Evolution of Medical and Dental Sciences, 9(36), pp.2630-2636.
Ashtankar, Poonam, V., PunamSawarkar., 2020. Role of PanchatiktaPanchaprasutikNiruhaVasti in Prediabetes A Case Report. International journal of ayurvedic medicine, 11, (3), pp. 588-93.

Baidya, A., Singh, S.K., Bajaj, S., Zargar, A.H., Singh, P., Das, S. and Shankar, A., 2020. Diabetes and covid-19: A review. Journal of the ASEAN Federation of Endocrine Societies, 35(1), p.40.

Belsare, A., Sawarkar, G. and Mahure, P., 2020. AN OBSERVATIONAL STUDY PROTOCOL FOR THE PREVALENCE OF NON-INSULIN DEPENDENT DIABETES MELLITUS IN DIFFERENT TYPES OF PRAKRUTI IN WARDHA CITY. International Journal of Modern Agriculture, 9(3), pp.96-99.

Huang, I., Lim, M.A. and Pranata, R., 2020. Diabetes mellitus is associated with increased mortality and severity of disease in COVID-19 pneumonia-a systematic review, meta-analysis, and meta-regression. Diabetes \& Metabolic Syndrome: Clinical Research \& Reviews, 14(4), pp.395-403.

Hussain, A., Bhowmik, B. and do Vale Moreira, N.C., 2020. COVID-19 and diabetes: Knowledge in progress. Diabetes research and clinical practice, p.108142.

Jankar, J.S., Harley, K.N., Mohod, K.M. and Babar, V.Y., Association of Urinary Albumin with HbA1c Levels in Subjects of Type 2 Diabetes Mellitus in Central India. Journal Of Evolution Of Medical And Dental SciencesJemds, 9 (52), 3921-25.

Kaple, M.N., MahaKalKar, C.C., KALE, A. and Shambharkar, S., 2020. Correlation of Metal Ions in Diabetic Patients. Journal of Clinical \& Diagnostic Research, 14(5).

Kosinski, C.H.R.I.S.T.O.P.H.E., Zanchi, A.N.N.E. and Wojtusciszyn, A., 2020. Diabète et infection à COVID19. Rev Med Suisse, 16, pp.939-943.

Kumar, A., Arora, A., Sharma, P., Anikhindi, S.A., Bansal, N., Singla, V., Khare, S. and Srivastava, A., 2020. Is diabetes mellitus associated with mortality and severity of COVID-19? A meta-analysis. Diabetes \& Metabolic Syndrome: Clinical Research \& Reviews, 14(4), pp.535-545.

Latchoumi, T.P., Ezhilarasi, T.P. and Balamurugan, K., 2019. Bio-inspired weighed quantum particle swarm optimization and smooth support vector machine ensembles for identification of abnormalities in medical data. SN Applied Sciences, 1(10), pp.1-10.

Muniyappa, R., Gubbi, S., 2020. COVID-19 pandemic, coronaviruses, and diabetes mellitus, Am JPhysiol Endocrinol Metab, 318(5), pp.736-741.

Pal, R. and Bhadada, S.K., 2020. COVID-19 and diabetes mellitus: An unholy interaction of two pandemics. Diabetes \& Metabolic Syndrome: Clinical Research \& Reviews, 14(4), pp.513-517.

Parveen, R., Sehar, N., Bajpai, R. and Agarwal, N.B., 2020. Association of diabetes and hypertension with disease severity in covid-19 patients: A systematic literature review and exploratory meta-analysis. Diabetes research 
and clinical practice, 166, p.108295.

Pugliese, G., Vitale, M., Resi, V. and Orsi, E., 2020. Is diabetes mellitus a risk factor for COronaVIrus Disease 19 (COVID-19)?. Acta diabetologica, pp.1-11.

Rajpal, A., Rahimi, L. and Ismail-Beigi, F., 2020. Factors leading to high morbidity and mortality of COVID-19 in patients with type 2 diabetes. Journal of diabetes, 12(12), pp.895-908.

Roncon, L., Zuin, M., Rigatelli, G. and Zuliani, G., 2020. Diabetic patients with COVID-19 infection are at higher risk of ICU admission and poor short-term outcome. Journal of Clinical Virology, 127, p.104354.

Shrivastava, P., Khatib, M.N., Gaidhane, S., Shrivastava, D., Gaidhane, A.M. and Zahiruddin, Q.S., 2020. Assessment of mean platelet volume (MPV) in subjects with Type 2 Diabetes Mellitus (T2DM) in a rural backdrop of central India. Medical Science, 24(101), pp.12-21.

Stehouwer, C.D., 2021. Observational research on severe COVID-19 in diabetes. The Lancet. Diabetes $\mathrm{Ct}$ Endocrinology, 9(2), p.56.

Tadic, M., Cuspidi, C. and Sala, C., 2020. COVID-19 and diabetes: Is there enough evidence?. The Journal of Clinical Hypertension, 22(6), pp.943-948.

Taher, N., Huda, M.S. and Chowdhury, T.A., 2020. COVID-19 and diabetes: What have we learned so far?. Clinical Medicine, 20(4), p.e87.

Vaibhav, T.,Khan, I.M., Gaikwad, S., 2020. Platelet Rich Fibrin Matrix the Cost Effective Way to Treat Trophic Ulcer in Diabetes: A Pilot Study. MEDICAL SCIENCE, 24(104), pp.2752-59.

Villabona, C.V., 2020. Commentary: COVID-19 and diabetes. diabetes research and clinical practice, 162.

Yaribeygi, H., Sathyapalan, T., Jamialahmadi, T. and Sahebkar, A., 2020. The Impact of Diabetes Mellitus in COVID-19: A Mechanistic Review of Molecular Interactions. Journal of Diabetes Research, 2020.

Zhang, Y., Cui, Y., Shen, M., Zhang, J., Liu, B., Dai, M., Chen, L., Han, D., Fan, Y., Zeng, Y. and Li, W., 2020. Association of diabetes mellitus with disease severity and prognosis in COVID-19: a retrospective cohort study. Diabetes research and clinical practice, 165, p. 108227.

Zhou, J. and Tan, J., 2020. Diabetes patients with COVID19 need better blood glucose management in Wuhan, China. Metabolism, 107(107), p.154216. 